
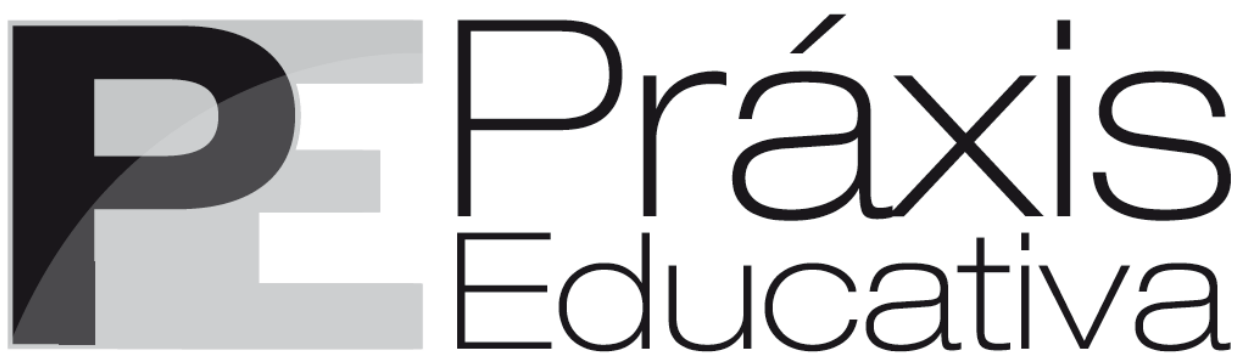

ISSN 1809-4309 (Versão online) DOI: 10.5212/PraxEduc.v.12i2.0011

\title{
Sobre masculinidades na Educação Física escolar: questões teóricas, horizontes políticos
}

\section{Masculinities in School Physical education: theoretical issues and political \\ horizons}

\section{Acerca de las masculinidades en la Educación Física escolar: cuestiones teóricas, horizontes políticos}

Leandro Teofilo de Brito ${ }^{*}$ Miriam Leite $^{* *}$

Resumo: A partir do reconhecimento da urgência da tematização das questões de gênero e sexualidade, na abordagem da inclusão da diferença na Educação Física escolar pela pesquisa acadêmica, focalizamos, neste artigo a noção de masculinidade. Apresentamos e problematizamos a teoria da masculinidade hegemônica, de Raewyn Connell, assim como a perspectiva queer, referências teóricas identificadas em levantamento bibliográfico que também é exposto. Com base na proposta da desconstrução, de Jacques Derrida, e da noção de gênero performativo, conforme desenvolvida por Judith Butler, finalizamos a reflexão com a proposição dos operadores de pesquisa masculinidade normalizadora e masculinidade queer, no desejo teórico-político de favorecer a abertura a uma inclusão mais radical nas pesquisas e aulas da EFE.

Palavras-chave: Educação Física escolar. Masculinidades. Perspectiva queer.

Abstract: Based on the recognition of the urgency of the theme of gender and sexuality within the approach of the difference inclusion in School Physical education by academic research, in this article, we focus the notion of masculinity. We present and problematize the Raewyn Connell's theory of hegemonic masculinity, as well as the queer perspective, theoretical references identified in the literature review, which is also exposed. Based on the proposal of Jacques Derrida's deconstruction and the notion of performative gender, as developed by Judith Butler, we conclude this reflection with the proposition of normalizing masculinity and queer masculinity as search operators, in the theoretical and political will to favor openness to a more radical inclusion in research and lessons of SPE.

Keywords: School Physical education. Masculinities. Queer perspective.

Resumen: Con base en el reconocimiento de la urgencia del tema del género y de la sexualidad, el enfoque de la inclusión de la diferencia en la Educación Física en la escuela por la investigación académica, nos centramos, en este artículo, en la noción de masculinidad. Presentamos y problematizamos la teoría de la masculinidad hegemónica, de Raewyn Connell, así como la perspectiva queer, referencias teóricas identificados en la revisión de literatura que también está expuesta. Sobre la base de la propuesta de la

\footnotetext{
* Doutorando em Educação - ProPEd/UERJ. E-mail: <teofilo.leandro@gmail.com>.

${ }^{* *}$ Professora da Universidade do Estado do Rio de Janeiro - UERJ. E-mail: <miriamsleite@yahoo.com.br>.
}

Práxis Educativa, Ponta Grossa, v. 12, n. 2, p. 481-500, maio/ago. 2017 Disponível em: <http://www.revistas2.uepg.br/index.php/praxiseducativa $>$ 
deconstrucción, de Jacques Derrida, y de la noción de género performativo, como el desarrollado por Judith Butler, concluimos la reflexión con la propuesta de los operadores de búsqueda masculinidad normalizadora y masculinidad queer, en la voluntad teórica y política para favorecer la apertura a una inclusión más radical en la investigación y en las enseñanzas de la EFE.

Palabras clave: Educación Física educativa. Masculinidades. Perspectiva queer.

A proposta da inclusão, sobretudo quando referida à educação escolar, tem sido com maior frequência associada à situação de pessoas com deficiências físicas e mentais (LEITE; FONSECA, 2013; SANTIAGO; SANTOS, 2015), o que pode contribuir, ao menos em alguma medida, para a manutenção de quadros de exclusão de outras manifestações da diferença. Se, de um lado, não julgamos possível, menos ainda desejável, qualquer tipo de hierarquização de discriminações e preconceitos na escola, por outro, no presente contexto político, entendemos que a crescente força do pensamento conservador no país outorga à luta pelo direito à diferença lésbica/gay/bissexual/transgênero (LGBT), contornos específicos, posto que a legitimidade da sua inclusão tem sido repetidamente colocada em questão por tais grupos políticos. Lamentavelmente, o ambiente escolar não se coloca como exceção nesse retrocesso.

Leite (2012), por exemplo, relata estudo etnográfico realizado em escola de ensino fundamental da rede pública municipal do Rio de Janeiro em que observou que, enquanto as chamadas deficiências físicas e mentais não eram alvo de discriminação explícita por parte de alunos, de professores ou de gestores, e o preconceito racial se colocava entre estudantes, mas não entre docentes da escola, alunos que externassem qualquer diferença relativamente às normas prevalentes na nossa sociedade quanto ao gênero e à sexualidade eram, cotidianamente, alvo de agressão e constrangimento. A autora pondera que a perspectiva da filantropia com relação às chamadas deficiências físicas e mentais e certo nível de condenação do racismo já se encontram relativamente fixados em nossas tradições culturais, porém, a crítica à heteronormatividade ${ }^{1}$ seria $^{2}$ ainda bastante recente.

Mencionamos tal estudo como exemplo do quadro recorrente que justifica a urgência e a pertinência da problematização das questões do gênero e da sexualidade na educação escolar, porém, não para propor a inversão da hierarquização que a pesquisadora afirma ter presenciado, o que configuraria apenas outro modo de afirmar essa hierarquia. Ressaltamos, nesse sentido, a flagrante distância que se coloca entre a tolerância filantropa e a perspectiva da inclusão: se estudantes com deficiências físicas e mentais podem muitas vezes contar com algum tipo de aceitação na escola da contemporaneidade, é sabido que isso não significa que se encontrem de fato incluídos. $\mathrm{Na}$ proposta da inclusão, para além da tolerância, pressupõe-se a transformação dos espaços escolares, de modo a contemplar as especificidades cognitivas e comportamentais de todos os estudantes, sem exceção. Deficiências físicas e mentais passam a ser entendidas como diferenças: modos de agir e de se expressar menos comuns na nossa sociedade, porém reconhecidos e respeitados nas suas particularidades, assim como se espera que ocorra com os demais alunos.

Contudo, é notória a dificuldade que temos encontrado na efetivação dessa perspectiva no dia a dia da escola. Entendemos que a Educação Física, pelos sentidos que, historialmente, foram-lhe atribuídos, configura disciplina particularmente resistente a tais proposições. Fosse na prática dos exercícios de condicionamento físico, com propósitos de disciplinarização e moralização, a partir de fundamentação na medicina e na biologia, fosse na opção pelo esporte,

\footnotetext{
${ }^{1}$ Normatização da ordem social que parte do pressuposto de que a heterossexualidade é natural, buscando controlar e regular a vida dos sujeitos, não apenas no que concerne à sua orientação sexual, como também na imposição de padrões de comportamentos atrelados a um suposto binarismo sexual (WARNER, 1993).
}

Práxis Educativa, Ponta Grossa, v. 12, n. 2, p. 481-500, maio/ago. 2017 Disponível em: <http://www.revistas2.uepg.br/index.php/praxiseducativa> 
este marcado por valores tradicionalmente atribuídos ao masculino, como virilidade, competitividade e força física (SOARES, 2006), a Educação Física escolar/EFE, desde sua institucionalização, ainda sob a denominação de Ginástica, no século XIX (CASTELLANI FILHO, 2013), tendeu a excluir ou subalternizar aqueles que não se enquadrassem nos padrões mais gerais da normatividade social. Rejeitam-se estudantes com deficiências físicas e mentais, mas também todos aqueles que se desviem do que se imponha como norma, por seu peso, timidez, habilidades motoras, identidade de gênero, orientação sexual - enfim, rejeitam-se todos os diferentes.

Sem negar a gravidade de todas as formas de exclusão na escola e a premência da sua problematização pela pesquisa acadêmica, focalizamos, neste artigo, o caso das identidades de gênero e das orientações sexuais, no contexto da EFE, reconhecendo o peso que tais práticas de discriminação e preconceito podem assumir, não apenas no âmbito da escola, como na sociedade em geral.

Temos poucas pesquisas de nível nacional que informem sobre a frequência e as feições das ocorrências de exclusão por fobia às populações LGBT. Entretanto, estudo da Secretaria de Direitos Humanos da Presidência da República/SDH-PR, realizado com ampla base de registros de denúncias - Disque Direitos Humanos, Central de Atendimento à Mulher, Disque Saúde, Ouvidoria do Sistema Único de Saúde/SUS, Conselho Nacional de Combate à Discriminação LGBT, Coordenação-Geral de Promoção dos Direitos de LGBT - e divulgado no ano de 2012, expõe que, de janeiro a dezembro de 2011, registraram-se 6.809 violações de direitos humanos contra essas populações, o que se traduz em uma média diária de 4,69 pessoas vitimadas por bi/homo/lesbo/transfobia. Entre tais pessoas, $67,5 \%$ se identificaram com o gênero masculino e $47,1 \%$ declararam idade entre 15 e 29 . No entanto, sabe-se que essas violações nem sempre são notificadas, sobretudo no que concerne a situações que têm lugar nas instituições escolares. É bem conhecido o fato de que eventos de discriminação por fobia a pessoas LGBT são comuns no dia a dia da escola e tendem a ser naturalizados como brincadeira juvenil, ou, quando se reconhece o constrangimento, em geral, culpabiliza-se a vítima (BENTO, 2011).

Outras duas pesquisas, também de escopo nacional, buscaram se aproximar da discriminação por gênero e por orientação sexual nas escolas. A Pesquisa sobre o preconceito e a discriminação no ambiente escolar ${ }^{3}$, realizada pela Fundação Instituto de Pesquisas Econômicas/FIPE e Instituto Nacional de Estudos e Pesquisas Educacionais Anísio Teixeira/INEP, em 2009, informa o impressionante percentual de $98,9 \%$ de respondentes que assumiram algum nível de distância social de homossexuais, enquanto 93,5\% declararam preconceito de gênero em maior ou menor grau. Já o estudo Diversidade sexual e homofobia no Brasil ${ }^{4}$, desenvolvido pela Fundação Perseu Abramo, nesse mesmo ano, em parceria com a Rosa Luxemburg Stiftung (fundação), da Alemanha, aponta que a maioria dos 423 entrevistados que se colocaram como homossexuais identificou a escola como o ambiente de maior ocorrência de práticas de discriminação, tanto por parte de estudantes, como pelos adultos que circulam nesse espaço.

\footnotetext{
2 Disponível em:

<http://www.rcdh.es.gov.br/sites/default/files/RELATORIO $\% 20$ VIOLENCIA $\% 20$ HOMOFOBICA $\% 20 A N O \%$ 202012.pdf>. Acesso em: 22 maio 2016.

3 Trata-se de survey que foi aplicado em 501 escolas distribuídas entre 27 estados brasileiros, envolvendo alunos do penúltimo ano do ensino fundamental, da última série do ensino médio e da Educação de Jovens e Adultos, além de professores e outros profissionais da Educação, responsáveis por estudantes e membros de Conselho Tutelar ou de associações de pais e mestres. Disponível em: <http://portal.mec.gov.br/dmdocuments/diversidade_apresentacao.pdf>. Acesso em: 17 maio 2016.

${ }^{4}$ A pesquisa foi realizada em 150 municípios do país. Disponível em: <www.fpabramo.org.br>. Acesso em: 17 maio 2016.
}

Práxis Educativa, Ponta Grossa, v. 12, n. 2, p. 481-500, maio/ago. 2017 Disponível em: <http://www.revistas2.uepg.br/index.php/praxiseducativa $>$ 
No entanto, não temos estudos de abrangência similar que identifiquem desdobramentos pedagógicos cotidianos da ação do preconceito contra pessoas LGBT na educação escolar. De fato, mesmo no âmbito dos estudos qualitativos da pesquisa em Educação, a focalização das temáticas do gênero e da sexualidade é relativamente recente. Em levantamento da abordagem das questões da diferença na Educação, publicado no ano de 2006 e referente aos trabalhos publicados nos anais das reuniões anuais da ANPEd/Associação Nacional de Pesquisa e PósGraduação em Educação, considerando-se a produção de todos os grupos de trabalho e de estudo, no período de 1994 a 2002, de um total de 94 textos selecionados, apenas 8 diziam respeito a tais questões (LEITE, 2006).

É significativo, porém, que, entre os 8 trabalhos que se ocuparam desses temas, 5 se reportem à condição da mulher e somente 3 se refiram à temática da orientação sexual, o que leva a autora a destacar a "incipiente discussão da homossexualidade, assunto que ganha cada vez mais espaço na sociedade brasileira, mas que parece ainda não estar incluído na pauta de reflexões prioritárias do campo da Educação" (LEITE, 2006, p. 87).

Chama também a atenção o fato de que 2 entre os 3 textos que abordam a temática da orientação sexual remetiam à Educação Física escolar (CUNHA JR; MELLO, 1996; FERRARI, 2000), que é denunciada como espaço de recorrente manifestação de hostilidade à diferença LGBT, inclusive por parte de professores. Em ambos os artigos, explicita-se a grave exclusão que decorre de tais preconceitos e discriminações.

Ferrari (2000, p. 3-4) relata observação de aula de Educação Física, em que o professor ridiculariza os que denomina como "boiolas", mas destacamos aqui a narrativa do autor acerca do comportamento, nessa situação, de um estudante identificado como homossexual, que evidencia o caráter excludente do preconceito por orientação sexual naquele espaço:

Dos três meninos que sempre estavam juntos e que, como Breno, não faziam aula, estava apenas um, em um canto. $\mathrm{O}$ grupo dos alunos organizou-se involuntariamente em um círculo ao redor do professor, exceto esse menino que estava visivelmente fora da roda, à margem, como que não se sentindo parte integrante do grupo, como se soubesse que aquele não era o seu grupo. Os amigos a quem ele sempre se juntava ainda não estavam no local, de forma que ele estava inibido, frágil diante do restante sem seus companheiros. Por outro lado, o grupo maior também parecia não o reconhecer como integrante, pois todos conversavam entre si e ninguém tinha assunto com ele. Isso demonstrava ainda mais seu isolamento.

No outro texto, localizado na revisão acima referida, Cunha Jr e Melo (1996, p. 21), apresentando discussão de entrevistas realizadas com homossexuais masculinos, sublinham que, entre os participantes da pesquisa, "os posicionamentos a respeito da Educação Física e da figura do professor no tratamento para com os homossexuais nos demonstrou um quadro alarmante. A Educação Física foi considerada uma das disciplinas mais discriminadoras do espaço escolar". A exclusão que pode advir desse quadro também é destacada pelos autores, que afirmam pretender "alertar acerca da necessidade de que as atividades físicas/esportivas não estejam restritas a determinados segmentos da população" (CUNHA JR; MELO, 1996, p. 19).

Passados 20 anos da publicação deste último artigo, Andres; Jaeger e Goellner (2015) observam que as questões de gênero e de sexualidade ganham maior visibilidade a partir do final da década de 1990, e sua tematização se encontra atualmente bastante ampliada. Concordamos com as autoras e podemos retomar a produção das reuniões da ANPEd como evidência de tais avanços: se no período de 1994 a 2002, identificam-se apenas 8 trabalhos que abordam esses temas, desde 2006, a Associação já conta com grupo de trabalho inteiramente voltado para as produções sobre Gênero, Sexualidade e Educação (GT 23).

Práxis Educativa, Ponta Grossa, v. 12, n. 2, p. 481-500, maio/ago. 2017 Disponível em: <http://www.revistas2.uepg.br/index.php/praxiseducativa> 
Entretanto, levantamentos mais recentes acerca dessa produção apontam que os estudos sobre a masculinidade têm sido menos desenvolvidos do que outros enfoques na pesquisa sobre gênero e sexualidade na Educação, o que também se aplica à Educação Física escolar.

Silva Jr e Canen (2015) publicaram pesquisa realizada a partir da busca em resumos de teses e dissertações da área da Educação, do período de 2007 a 2010, disponibilizados no Banco de Teses e Dissertações da Coordenadoria de Aperfeiçoamento de Pessoal de Nível Superior/CAPES e na Biblioteca Digital da Universidade de São Paulo/USP. Informam que, utilizando o descritor masculinidade, localizaram apenas 3 dissertações e 2 teses ${ }^{5}$ que versavam sobre essa temática. Também Devide et al. (2011) relataram estudo com focalização semelhante, porém voltado especificamente para a Educação Física e valendo-se de outra base de dados. No Diretório de Grupos de Pesquisa do Conselho Nacional de Desenvolvimento Científico e Tecnológico/CNPq, identificaram os coletivos já consolidados na área da Educação Física que referiam o termo gênero na denominação do grupo e/ou da linha de pesquisa de vinculação, ou ainda nos objetivos anunciados na sua apresentação. Conclui-se que:

\footnotetext{
Duas questões podem ser levantadas pelos resultados encontrados: o foco dos estudos de gênero na EF ainda mantém associação com os estudos das mulheres; talvez, pelos estudos de gênero serem derivados dos estudos sobre mulheres e terem acompanhado o movimento feminista; e nenhuma linha de pesquisa ou projeto sobre Estudos de Gênero com foco nos homens ou na masculinidade foi identificado, reforçando a necessidade desta área de pesquisa ampliar o foco das investigações [...] (DEVIDE et al., 2011, p. 99).
}

Apostando, contudo, na potencialidade teórica e política da discussão também das identidades masculinas, na abordagem das questões da inclusão da diferença de identidade de gênero e de orientação sexual na Educação Física escolar, focalizamos, neste artigo, a noção de masculinidade 6 . Seguimos desenvolvendo, no próximo item, a justificativa desse recorte, que também inclui a explicitação da perspectiva teórica que orientou o estudo que aqui se expõe. Problematizamos, na sequência, a noção de masculinidade hegemônica, identificada como a teorização mais citada na pesquisa bibliográfica que empreendemos, em complementação aos levantamentos acima mencionados. Finalizamos esta reflexão propondo as noções/operadores de pesquisa masculinidade normalizadora e masculinidade queer, com o propósito teórico-político de abertura a uma inclusão mais radical nas pesquisas e práticas da EFE, relativamente às questões do gênero e da sexualidade.

\footnotetext{
5 GOMES, L. M. de A. L. Representações de masculinidades entre os jovens em Moçambique em tempos de SID A. 2007. 121 f. Dissertação (Mestrado em Educação) - Faculdade de Educação, Universidade Federal do Rio Grande do Sul, Porto Alegre. 2007; SILVA, M. M. Entre a ilha deserta e o arquipélago: mapeamentos e cartografias das masculinidades produzidas nas aulas de educação física. 2008. 216 f. Dissertação (Mestrado em Educação) - Setor de Educação, Universidade Federal do Paraná, Curitiba, 2008; ROSA, R. M. Corpos híbridos na docência: experiências, narrativas de si (des)construção das masculinidades no magistério. 2009. 116 f. Dissertação (Mestrado em Educação) - Centro de Ciências Humanas e da Educação, Universidade do Estado de Santa Catarina, Florianópolis, 2009; BRITO, R. dos S. Masculinidades, raça e fracasso escolar: narrativas de jovens na educação de jovens e adultos em uma escola pública municipal de São Paulo. 2009. 325 f. Tese (Doutorado em Educação) - Universidade de São Paulo, São Paulo. 2009; SILVA, L. R. G. Sexualidade e orientação sexual na formação de professores: uma análise da política educacional. 2010. $153 \mathrm{f}$. Tese (Doutorado em Educação) - Faculdade de Ciências e Letras. Universidade Estadual Paulista, Araraquara. 2010.

${ }^{6}$ Estudo realizado na interseção da pesquisa de doutorado Masculinidades performativas em narrativas de jovens atletas: desconstruções, de Leandro Teofilo de Brito, com o projeto Diferença e desigualdade na educação escolar do jovem adolescente: desconstruçẽes, desenvolvido pelo Grupo de Estudos sobre Diferença e Desigualdade na Educação Escolar da Juventude/DDEEJ, sob coordenação da professora Miriam Leite, também orientadora da referida pesquisa de doutorado; ambos trabalhos são vinculados à linha de pesquisa Infância, Juventude e Educação, no Programa de PósGraduação em Educação da Universidade do Estado do Rio de Janeiro/ProPEd-UERJ.
}

Práxis Educativa, Ponta Grossa, v. 12, n. 2, p. 481-500, maio/ago. 2017 Disponível em: <http://www.revistas2.uepg.br/index.php/praxiseducativa > 


\section{Desestabilizar o masculino, desconstruir o preconceito}

A abordagem das questões da masculinidade nos estudos de gênero encontra, muitas vezes, resistência em parcela da militância feminista, que critica o que é interpretado como invasão do seu espaço de luta política. Além disso, argumenta-se que a concepção relacional da construção do feminino, proposição que sustenta a inclusão da temática da masculinidade nos estudos de gênero, poderia reforçar tradições androcêntricas de subalternização e dependência da mulher - algo como uma atualização do mito da costela de Adão.

Sem contestar a necessidade da permanente vigilância quanto ao surgimento de novas formas de afirmação de privilégios masculinos, defendemos que, a depender da noção de gênero adotada, pode-se pensar em uma significação do feminino construída em modo relacional, porém concebendo tal relação em registro precário e não hierarquizante.

A teórica feminista Joan Scott, em artigo sugestivamente intitulado Os usos e abusos do gênero (SCOTT, 2012, p. 328), comenta sobre a ampla difusão do termo, que poderia resultar na perda da

função de desestabilizador radical das pressuposições sobre a relação entre sexo biológico e papéis construídos culturalmente para mulheres e homens, trabalho que havia sido feito nos anos de 1970, quando feministas norte-americanas e inglesas apropriaram-se do termos dos sexologistas e psiquiatras como John Money e Robert Stoller.

Presente também em documentos de órgãos públicos locais e internacionais, tem nomeado, com frequência, o coletivo das mulheres, em simplificação que ignora o que entendemos como importantes construções teórico-políticas de tendências do pensamento feminista que se aproximam de proposições do pós-estruturalismo.

A rejeição do caráter fixo e permanente da oposição binária que se expressa na dicotomia homem-mulher/macho-fêmea/masculino-feminino é defendida por Joan Scott, com base na perspectiva da desconstrução proposta pelo filósofo franco-argelino Jacques Derrida. Essa perspectiva foi apropriada por várias teóricas feministas, dentro dos estudos de gênero e sexualidade, mais especificamente, naqueles situados na terceira onda do movimento feminista, como mais um caminho para subverter a construção hierárquica que se naturaliza na suposição da diferença sexual.

O movimento de contestação desses binarismos, pela desconstrução, tão caro ao ativismo feminista e tão potente politicamente nas lutas pelos direitos à diferença, trouxe às discussões sobre gênero e sexualidade novas configurações e alternativas, e é sintetizado por Joan Scott nos seguintes termos:

\footnotetext{
Disputas quanto ao significado implicam na introdução de novas oposições, na reversão de hierarquias, na tentativa de expor termos reprimidos, de contestar o estatuto natural de pares aparentemente dicotômicos e de expor sua interdependência e sua instabilidade interna. Esse tipo de análise, teorizada por Jacques Derrida como 'desconstrução', torna possível estudar sistematicamente (ainda que não definitivamente ou totalmente) os processos conflitivos que produzem o significado (SCOT'T, 1994, p. 21).
}

Em acordo com essa apropriação da proposta derridiana da desconstrução, ressaltamos que focalizar a discussão da masculinidade não precisa implicar em secundarização da atenção às opressões da mulher e do sexismo: uma vez que não é possível, para a pesquisa acadêmica, abordar a totalidade social, recortes temáticos não se justificam pela exclusividade da sua relevância intelectual ou política - na abordagem das questões da inclusão na EFE, há muito o 
que estudar, o que inclui o feminino e o masculino, em sua heterogeneidade interior, bem como nas disputas sociais que se dão pela sua significação.

Nessa perspectiva, voltamos nossa atenção para a problematização da noção de masculinidade, apostando na sua potencialidade teórica e política. Propomos que sua desconstrução, no âmbito dos estudos de gênero na Educação Física, fortalece de modo radical o combate ao preconceito e à discriminação heteronormativa que se percebe tão recorrente nas práticas escolares dessa disciplina, na medida em que permite contestar a normatização de comportamentos e desejos sexuais, sem propor em seu lugar novas amarras identitárias. Apoianos também nesse projeto, a noção de gênero performativo desenvolvida por Judith Butler (2015a, 2015b, 2012, 1997), do mesmo modo, em diálogo com autores do pós-estruturalismo, como Derrida e Foucault.

O termo performativo, apropriado por Judith Butler em seus estudos sobre gênero e sexualidade, tornou-se conhecido pela sua mais famosa obra traduzida para o português: Problemas de gênero: feminismo e subversão de identidade, mas foi no livro Excitable speech (1997) onde expôs em maior detalhe essa formulação. A apropriação do termo pela autora se deu a partir da desconstrução derridiana da teoria dos atos de fala, do linguista John L. Austin. No campo da Linguística, Austin foi autor importante nas soluções teóricas para o problema do significado, especialmente entre estudiosos e estudiosas que procuravam incluir o uso cotidiano da linguagem na descrição dos sentidos linguísticos (PINTO, 2009).

Judith Butler (2015a) se apropria dessas teorizações para enunciar a noção de performatividade de gênero, que nomeia a repetição estilizada de falas, gestos, atuações e encenações que, por meio da linguagem, constitui e regula tanto o gênero como o sexo e a sexualidade, a partir de padrões que se impõem como normativos, como a heterossexualidade reprodutora. Contudo, a concepção performativa do gênero também admite a possibilidade de deslocamentos nos seus sentidos, enfatizando-se não haver uma identidade de gênero anterior às expressões de gênero:

Se a verdade interna do gênero é uma fabricação, e se o gênero verdadeiro é uma fantasia instituída e inscrita sobre a superfície dos corpos, então parece que os gêneros não podem ser nem verdadeiros e nem falsos, mas somente produzidos como efeitos da verdade de um discurso sobre a identidade primária e estável (BUTLER, 2015a, p. 236).

O gênero, segundo a autora, remete-se ao aparato pelo qual a produção e a normalização do masculino e do feminino se manifestam em sociedade, sem fundamentação necessária em conformações hormonais, cromossômicas ou fisiológicas. Desse modo, conceber que o gênero sempre e exclusivamente supõe as matrizes masculina e feminina é perder de vista o ponto crítico do reconhecimento de que essa produção coerente e binária é contingente, não decorrendo, portanto, de nenhuma necessidade estrutural.

A contestar o binarismo masculino/feminino, Butler (2015b) afirma que os sujeitos são constituídos mediante normas que, quando repetidas, produzem, mas também podem deslocar os sentidos dos termos por meio dos quais são reconhecidos. Postula, desse modo, uma ontologia historialmente contingente, que impede qualquer compreensão determinística, seja de normatizações, seja de seus deslocamentos. 
O gênero é o mecanismo pelo qual as noções de masculino e feminino são produzidas e naturalizadas, mas gênero pode muito bem ser o aparato através do qual esses termos podem ser desconstruídos e desnaturalizados (BUTLER, 2012, p. 70; tradução nossa7).

Pensar em masculinidades segundo a noção de gênero performativo, como este trabalho propõe, é pensar nos inúmeros e incontroláveis sentidos atribuídos ao masculino em performances cotidianas e/ou eventuais, distanciando-se de modelos normativos e essencialistas de leitura sobre a identidade de gênero. E mais: é situar as masculinidades em um jogo de relações e disputas, jogo do qual também faz parte a produção acadêmica.

A partir dessa perspectiva, diante dos poucos trabalhos que discutem questões da masculinidade localizados por Silva Jr e Canen (2015) e Devide et al. (2011), realizamos novo levantamento bibliográfico, a partir de outras fontes, visando conhecer mais sobre a abordagem dessa temática na pesquisa acadêmica sobre a Educação Física escolar. Assim, revisamos as publicações dos periódicos Motriz, Movimento e Revista Brasileira de Educação Física e Esportes, especializados em Educação Física, no decênio de 2006 a 2015. Tratando-se de periódicos qualificados na faixa A1-B1 na classificação Qualis-2014 ${ }^{8}$, supomos impacto potencial de relevo de tais publicações, que são procuradas, para leitura e publicação, por pesquisadores de prestígio no país. Contudo, reconhecendo a alta seletividade para publicação nesses periódicos, averiguamos também a presença da discussão da masculinidade em anais de congresso tradicional desse campo de estudo, de modo a ampliar o escopo da pesquisa. Investigamos, então, os anais do Conbrace/Conice ${ }^{9}$ (Congresso Brasileiro de Ciências do Esporte/Congresso Internacional de Ciências do Esporte), também no período de 2006 a 2015.

De fato, nesses outros recortes e bases de dados, pudemos localizar um maior quantitativo de artigos e pesquisas que se ocuparam da discussão da masculinidade no âmbito da EFE. Foi então possível identificar a teoria da masculinidade hegemônica, desenvolvida pela teórica australiana Raywen Connell como a fundamentação mais recorrente nesses estudos, mas também localizamos um número significativo de trabalhos que referem autores e argumentos de perspectivas pós-estruturalistas, como se expõe a seguir.

\section{Masculinidades}

A teoria da masculinidade hegemônica preponderou nos artigos publicados nos periódicos em questão, fundamentando 5 entre os textos selecionados a partir da articulação dos descritores masculinidade/educação física/escola/educaşão ${ }^{10}$ (SILVA; BOTELHO-GOMES; GOELLNER, 2008; SANCHO et al., 2010; ANDREOLI, 2011; BRITO; SANTOS, 2013; PASSOS et al., 2014). Tal referência também esteve presente em trabalhos publicados no

\footnotetext{
7 "El género es el mecanismo a través del cual se producen y se naturalizan las nociones de lo masculino y lo feminino, pero el género bien podría ser el aparato a través del cual dichos términos se desconstruyen y se desnaturalizan".

${ }^{8}$ Disponível em:

<https://sucupira.capes.gov.br/sucupira/public/consultas/coleta/veiculoPublicacaoQualis/listaConsultaGeralPerio dicos.jsf>. Acesso em: 22 maio 2016.

${ }_{9}^{9}$ Disponíveis em: <http://cbce.tempsite.ws/congressos/index.php/index/index>. Acesso em: 29 maio 2016.

10 Revista Motriz: total de artigos revisados - 572, total de artigos selecionados - 3, total de artigos com base na noção de masculinidade hegemônica - nenhum; Revista Movimento: total de artigos revisados - 377, total de artigos selecionados - 4, total de artigos com base na noção de masculinidade hegemônica - 3; Revista Brasileira de Educação Física e Esportes: total de artigos revisados - 427, total de artigos selecionados - 2, total de artigos com base na noção de masculinidade hegemônica - 2 .
}

Práxis Educativa, Ponta Grossa, v. 12, n. 2, p. 481-500, maio/ago. 2017 Disponível em: <http://www.revistas2.uepg.br/index.php/praxiseducativa> 
Conbrace/Conice (KINIJNIK et al., 2007; ALMEIDA, 2015), embora sem a predominância que se verificou nos periódicos pesquisados. Vale destacar, no entanto, que, nos trabalhos selecionados nos anais desses encontros, não se recorreu a nenhuma outra teorização voltada especificamente para a questão da masculinidade. Muitos autores são citados nesses trabalhos, como Bourdieu e Marx, porém, nesses casos, o termo masculinidade foi mobilizado em seu sentido dicionarizado, sem referencial teórico específico.

Raewyn Connell, pesquisadora e socióloga australiana, desenvolve, na década de 1980, no âmbito dos men's studies ${ }^{11}$, a teorização da masculinidade hegemônica (CONNELL, 2014, 2013, $2003,2000,1995)$. Buscando ir além da teoria dos papéis sexuais ${ }^{12}$, muito discutida entre os anos de 1950 e 1970, por julgar que secundarizavam as questões de poder existentes no contexto das relações entre homens e mulheres, a noção de masculinidade hegemônica se refere à dinâmica cultural por meio da qual parte dos homens exige e mantém uma posição de liderança nas sociedades ocidentais, através da legitimação do patriarcado, submissão das mulheres e, em especial, da exclusão de masculinidades consideradas subalternas.

A masculinidade hegemônica pode se definir como a configuração de prática de gênero
que incorpora a resposta aceita, em um momento específico, ao problema da
legitimidade do patriarcado, que garante (ou se presume garantir) a posição dominante
dos homens e a subordinação das mulheres (CONNELL, 2003, p. 117, tradução
nossa ${ }^{13}$ ).

Apropriando-se da noção de hegemonia de Antonio Gramsci, Connell (1995) afirma que grupos de homens lutam por uma posição dominante, através da definição social da masculinidade, buscando assim obter vantagens materiais e psicológicas na ordem do gênero. Cabe sublinhar que a socióloga afirma considerar a relação historicamente móvel entre as classes sociais na noção de hegemonia, para fazer este paralelo em sua abordagem sobre a masculinidade. Para a autora, a masculinidade hegemônica se encontra em posição dominante na estrutura hierárquica das relações de gênero, compostas também, de modo subalterno, pelas mulheres e por masculinidades tidas como inferiores.

O conceito de gênero, para a autora, define-se como a estrutura de relações sociais, centradas na arena reprodutiva do corpo, o que engloba também o conjunto de práticas que trazem as distinções reprodutivas para os processos sociais (CONNELL; PEARSE, 2015).

Connell (1995) argumenta que a construção da masculinidade se dá por meio de projetos coletivos e individuais submetidos a instituições e forças culturais. Explicita, literalmente, sua perspectiva estruturalista (CONNELL; PEARSE, 2015), destacando a ação do Estado, das instituições de larga escala e das relações econômicas, na discussão do gênero e da masculinidade.

Nas sociedades contemporâneas, as estruturas econômicas e de poder envolvem instituições de grande escala. Portanto, uma parte chave do estudo de masculinidades é pesquisar não somente indivíduos, mas instituições inteiras, nas quais as masculinidades se encontram incrustadas, e que possuem peso na escala social. Isso inclui o Estado, os

\footnotetext{
${ }^{11}$ Sob essa denominação, que não costuma ser traduzida para o português, emerge nos países de origem anglo-saxã, ao longo da década de 1980, um conjunto de estudos sobre a construção social das masculinidades, protagonizados por pesquisadores homens, em sua maioria, vinculados explicitamente a movimentos feministas (CECCHETTO, 2004).

12 A teoria dos papéis sexuais buscava analisar os comportamentos normativos masculinos e femininos, reforçando, entretanto, a concepção de distinção entre sexo biológico e gênero (FORTH, 2013).

13 "La masculinidad hegemônica puede definirse como la configuración de la práctica de género que incorpora la respuesta aceptada, en un momento específico, al problema de la legitimidad del patriarcado, lo que garantiza (o se considera que garantiza) la posición dominante de los hombres y la subordinación de las mujeres".
}

Práxis Educativa, Ponta Grossa, v. 12, n. 2, p. 481-500, maio/ago. 2017 Disponível em: <http://www.revistas2.uepg.br/index.php/praxiseducativa $>$ 
serviços de segurança, corporações, os mercados de capital e de commodities (CONNELL, 2013, p. 326).

A autora também propôs uma classificação de hierarquia das masculinidades subalternas à hegemônica, nomeadas como cúmplices, subordinadas e marginalizadas, designando tal processo como dinâmica das masculinidades (CONNELL, 2003). Postula, então, que a masculinidade hegemônica não é necessariamente o padrão mais comum de realização do ser homem, embora seja o modelo legitimado a ser seguido pelos que dessa forma se identifiquem, e que outras masculinidades coexistem e são simultaneamente produzidas, em diferentes contextos sociais (CONNELL, 2000).

Afirma, ainda que, mesmo a masculinidade hegemônica sendo um modelo normativo, o quantitativo de homens que vivenciam rigorosamente o seu padrão pode ser muito pequeno. Dessa forma, muitos sujeitos masculinos obtêm vantagens advindas de tal modelo, beneficiandose dos dividendos patriarcais, em especial da subordinação das mulheres, mesmo que não se enquadrem plenamente nas práticas instituídas pela masculinidade hegemônica. Estas seriam as masculinidades cumplices (CONNELL, 2003).

Os homens homossexuais, em situação de franca subalternização pelos homens heterossexuais, representariam a masculinidade subordinada. As relações de dominação e de subordinação específicas desse modelo se dariam pela estigmatização cultural homofóbica da identidade gay, através de uma série de práticas materiais e simbólicas, tais como exclusões culturais e políticas, discriminação religiosa e econômica, violências de todos os tipos etc. "A opressão coloca as masculinidades homossexuais na parte inferior da hierarquia entre os homens [...]" (CONNELL, 2003, p. 119, tradução nossa ${ }^{14}$ ). Defende que a subordinação desse tipo de masculinidade se expressa também pela fabricação de termos que buscam ofender homens heterossexuais identificando-os como homossexuais, tais como "maricas", "bicha".

Por fim, a masculinidade marginalizada diz respeito a exclusões relacionadas a questões de classe social e raça/etnia. Connell (2000) pondera que as masculinidades marginalizadas podem partilhar de características associadas à hegemônica, mas que essa autorização - advinda da própria masculinidade hegemônica - nunca é plena, nem tampouco beneficia todo o grupo de homens classificados neste modelo. O exemplo mais clássico diz respeito aos atletas negros estadunidenses, que podem eventualmente se aproximar do modelo hegemônico de masculinidade, pelo status, fama e dinheiro conquistados pela carreira, porém não o fazem sem restrições, nem implicando qualquer alteração para a situação dos homens negros em geral (CONNELL, 2003).

Embora tenha sido amplamente apropriada por pesquisadores e pesquisadoras nos estudos sobre homens e masculinidades, críticas foram feitas à noção de masculinidade hegemônica ao longo dos anos, e, em resposta, Raewyn Connell, em parceria com James Messerschmidt, repensou o conceito, em artigo publicado no ano de 2005, na revista Gender \& Society, e traduzido para o português em 2013, pela Revista Estudos Feministas. Connell e Messerschmidt (2013) resgatam, em síntese, a história do conceito, formulado a partir de uma pesquisa realizada em escolas australianas, no início da década de 1980, e, posteriormente, sistematizado em artigo publicado pela socióloga, em coautoria com Carrigan e Lee, no ano de 1985, este ainda não publicado no Brasil. O artigo criticava extensivamente o entendimento sobre o masculino dentro da teoria dos papéis sociais, ressaltando a ausência de problematizações sobre as relações de poder que perpassavam a construção e a manutenção de tais papéis. Ainda segundo Connell e Messerschmidt (2013), a fonte mais citada para referir a teoria da masculinidade

14 “La opresión coloca las masculinidades homosexuales en el fondo de una jerarquia entre los hombres [...]”. 
hegemônica vem da obra Gender and Power, de 1987, não traduzida, na qual o conceito foi explanado de forma mais detalhada do que no texto inicial.

Nessa revisitação à teoria da masculinidade hegemônica, não apenas resgatam argumentações que a contestam, como também discutem sua operacionalização em pesquisas que a tomaram como fundamentação. Embora atribuam parte das críticas recebidas a formas de desenvolvimento dessas operacionalizações que não seriam intrínsecas à teorização em questão, apontam dois aspectos das suas formulações iniciais que julgam merecer revisão: 1) o modelo de relações sociais estabelecidas a partir da masculinidade hegemônica, que afirmam que deve ser complexificado e passar a incluir os múltiplos padrões de exercício de poder e de dominação que podem ter lugar em tais processos - "Claramente, melhores formas de compreender as hierarquias de gênero são necessárias"; 2) o entendimento das masculinidades a partir de conjuntos de traços característicos, concepção que deveria ser superada por favorecer abordagens essencialistas - "Não apenas o conceito essencialista de masculinidade, mas também, em geral, a abordagem dos traços para compreender o gênero necessitam ser completamente transcendidos" (CONNELL; MESSERSCHMIDT, 2013, p. 264).

A autora e o autor propõem, então, quatro eixos teóricos para a efetivação dessas revisões: 1) um entendimento mais holístico da hierarquia de gênero, em que se reconhecem as possibilidades de agência de grupos subordinados nessa ordem; 2) o desenvolvimento de uma geografia das configurações da masculinidade, identificando-se a existência de masculinidades locais, regionais e globais, com destaque para a sua interseccionalidade; 3) maior ênfase na discussão da incorporação social da masculinidade; 4) a manutenção da dinâmica das masculinidades, porém considerando-se mudanças nas conformações do modelo dominante, a partir das lutas sociais de mulheres e grupos gays, mas também com atenção à heterogeneidade interna às categorias das masculinidades.

Raewyn Connell reafirma, no entanto, que estruturas como Estado, economia, religião e trabalho mostram-se mais importantes nas discussões sobre gênero e masculinidades do que as perspectivas pós-estruturalistas costumam reconhecer, conforme declara em entrevista concedida em passagem pelo Brasil:

Internacionalmente, a maior mudança nos estudos de gênero, nos últimos 30 anos, foi a gigantesca influência das ideias pós-estruturalistas, até chegarmos ao ponto em que gênero é frequentemente definido em termos de discurso e identidade. Mas eu acho que, agora, os ganhos deste giro discursivo estão exauridos. Eu espero que a nova trajetória possa prestar mais atenção a assuntos econômicos, não no velho formato de um modelo de capitalismo simplificado, mas analisando a dinâmica econômica global nas relações de gênero (RODRIGUES; ANDRADE; MANO, 2015, p. 49).

Em publicação anterior (CONNELL, 2014, p. 22), já havia criticado "boa parte da discussão pós-estruturalista a respeito da performatividade", por reduzir as práticas de gênero "a repetições intermináveis, citações", contra-argumentando que as "estruturas de gênero realmente mudam historicamente, existem momentos de crise e de transformação estrutural".

A produtividade da teorização de Connell para a reflexão sobre a inclusão daqueles que fogem aos padrões da heteronormatividade prevalente, nas práticas escolares da Educação Física, é atestada pela sua recorrente referência em trabalhos que abordam tal temática, conforme já destacado. Porém, não apenas pela recorrência da sua menção reservamos fração tão extensa desta reflexão para a sua abordagem: a proposição da existência de múltiplas possibilidades de vivência da masculinidade, bem como sua vinculação às estruturas de poder que se fundam no sexismo, representam ganho teórico e político que não faria sentido ignorar ou diminuir. Entretanto, discordamos das críticas da autora à teorização da performatividade do gênero, que

Práxis Educativa, Ponta Grossa, v. 12, n. 2, p. 481-500, maio/ago. 2017 Disponível em: <http://www.revistas2.uepg.br/index.php/praxiseducativa $>$ 
avaliamos como particularmente potente para os estudos sobre essas questões na contingência do dia a dia da educação escolar, na medida em que permite reconhecer a força das repetições, mas também dos deslocamentos que se enunciam nesses ambientes.

Sem supô-los autônomos - o que contradiria os postulados mais basilares das teorizações da desconstrução e da performatividade - julgamos que essa abordagem favorece a abertura da pesquisa acadêmica à complexidade de tais ambientes. Para além do reflexo de macroestruturas, a educação escolar é cenário multifacetado que abriga permanentes disputas por normatizações de sentidos, com vigor local e possibilidades não necessariamente controláveis de subversão das estabilizações que se afirmam em contextos sociais mais amplos. Não parece demais lembrar que o pós-estruturalismo não nega a existência do que se pode chamar de estruturas, porém recusa enfaticamente sua unicidade, fixidez e previsibilidade. No chão da escola, entrecruzam-se numerosos (infinitos?) vetores de significação que evidenciam a multiplicidade e a precariedade das estruturas que a afetam, mas que também são por ela afetadas.

Em atenção a esse quadro, autoras e autores que se ocupam do preconceito e da discriminação por questões de gênero e de orientação sexual nas aulas de Educação Física têm se aproximado de perspectivas pós-estruturalistas, conforme discutimos a seguir.

\section{Multidões}

Embora não tenhamos localizado outras conceituações de masculinidade no levantamento bibliográfico que realizamos, identificamos importante recorrência na fundamentação teórica de trabalhos que se ocuparam dessa temática sem se remeter à teoria da masculinidade hegemônica: conforme já assinalado por Devide et al. (2011), tem crescido a produção acadêmica da área da Educação Física que dialoga com autoras e autores de perspectivas pós-estruturalistas. Em nosso estudo sobre as publicações em periódicos desse campo, identificamos em Santos (2010), Moioli et al. (2014) e Anjos (2015) apropriações diversas dessa interlocução, bem como nos trabalhos de Goetems e Schwengber (2013) e Chaves (2015), que localizamos nos anais do Conbrace/Conice pesquisados.

Com metodologias e recortes empíricos distintos, as pesquisas relatadas nesses artigos convergem na denúncia da repetição e da naturalização de padrões de masculinidade associados à heteronormatividade. Entretanto, Chaves (2015) avança para além da denúncia, quando, com base na teoria queer, relata pesquisa sobre um time de voleibol universitário do Rio Grande do Norte, composto por jovens atletas que se identificavam como gays. A autora destaca a afirmação da sexualidade dos sujeitos entrevistados em relação à família, torcida e instituição esportiva tradicional, e argumenta que, mesmo que em meio a situações de homofobia vividas pelos atletas, deslocamentos importantes se faziam presentes no enfrentamento das normas e regulações no campo do esporte. Sem negar a pertinência da denúncia na abordagem das questões da diferença na educação escolar, enfatizamos a produtividade da perspectiva queer, que permitiu identificar e valorizar as manifestações de resistência à bi/homo/lesbo/transfobia que, apesar da força das enunciações conservadoras, insiste em se colocar nos diferentes espaços da Educação Física.

A teoria queer busca problematizar a heterossexualidade como norma, como um modelo compulsório a ser seguido e incorporado pelos sujeitos, assim como questionar o binarismo recorrente nas identificações de gênero. Destacam-se aquelas e aqueles que, além de não se conformarem com um modelo heterocentrado para viver seus desejos, desestabilizam o sistema dicotômico e fixo de identidade com sua própria performance de gênero, que transcende o binarismo masculino/feminino. 
Localiza-se o surgimento dessa teoria nos EUA, na segunda metade da década de 1980, a partir da epidemia da aids (MISKOLCI, 2013; LOURO, 2008; SPARGO, 2006). Nesse período, discursos reacionários do governo estadunidense recusaram-se a reconhecer a doença como emergência de saúde pública, associando-a, exclusivamente, à população gay, o que reconfigurou a homofobia no país, gerando um novo processo de repulsa à homossexualidade, após a fase mais amena da chamada revolução sexual. Como resposta, as reações de gays e lésbicas foram radicais, culminando em uma apropriação desconstrutora do termo queer que reverteu seu sentido de ofensa e insulto, como forma de resistência à exclusão social vivida por sujeitos de identificações de gênero e sexualidade não normativas naquele contexto.

Queer, anteriormente, constituía um xingamento e uma forma bastante pejorativa de se referir a homossexuais e também trazia o sentido de estranho e/ou ridículo (LOURO, 2008). Com toda sua carga de estranheza e marginalidade, o termo queer foi assumido pelo movimento homossexual e lésbico a partir de uma perspectiva de oposição e contestação, que não apenas ressignificou a expressão linguística, como também afetou importante parcela do movimento. Nesse sentido, Miskolci (2013, p. 24-25) destaca que

Em sua maior parte, o movimento homossexual emerge marcado por valores de uma classe-média letrada e branca, ávida por aceitação e até mesmo incorporação social. Algo muito diverso se passa quando surgem movimentos queer, que se pautarão menos na demanda de aceitação ou incorporação coletiva e focarão mais na crítica às exigências sociais, aos valores, às convenções culturais como forças autoritárias e preconceituosas.

Emergiu, nesse contexto, uma nova política de gênero - New gender politics (BUTLER, 2012) - ou o que se pode chamar de uma política queer, pois a luta por direitos e reconhecimento passa a não ser só do movimento homossexual e lésbico, mas do que se denomina movimento LGBT $^{15}$, abarcando um sem número de possibilidades de identificações dos gêneros e das sexualidades nos sujeitos, e tomando como base e propósito a desconstrução das normas e das convenções que buscam regular e padronizar até mesmo gays e lésbicas.

Nessa direção, os estudos acadêmicos disseminaram, nas universidades, esse novo entendimento sobre gênero e sexualidade, questionando-se a heterossexualidade como norma e colocando-a, do mesmo modo que a homossexualidade, como uma construção social, com base em autoras como Eve Sedgwick, Judith Butler e Teresa de Lauretis - de fato a centralidade na produção acadêmica inicial da teoria queer foi estadunidense (MISKOLCI, 2013).

Conforme Spargo (2006), queer é um termo que se define, independentemente de funcionar como substantivo, adjetivo ou verbo, contra o normal ou normatizado. Um quadro que não pode ser considerado singular, conceitual ou sistemático, mas, sim, reconhecido por meio de compromissos intelectuais relacionados a questões sobre gênero, sexo e sexualidade uma escola de pensamento com visão heterodoxa. Para a autora, o queer descreve um leque diverso de práticas relacionadas a críticas ao sistema sexo-gênero, afirmando o direito à existência de sexualidades não normativas, das pessoas transgênero binárias e não binárias, dos desejos transgressivos, como o sadomasoquismo, entre outros.

\footnotetext{
15 A sigla LGBT remete a lésbicas, gays, bissexuais e transgêneros, incluindo, em algumas concepções, as siglas I, de intersexual, e Q, de queer. Pode-se, no entanto, contestar a inclusão do queer na sigla, posto que essa perspectiva não pretende se colocar como uma nova identidade, mas, sim, desestabilizar a própria noção de identidade.
}

Práxis Educativa, Ponta Grossa, v. 12, n. 2, p. 481-500, maio/ago. 2017 Disponível em: <http://www.revistas2.uepg.br/index.php/praxiseducativa $>$ 
Ex-orientanda de Jacques Derrida, Beatriz Preciado ${ }^{16}$ propõe a noção de contrassexualidade, na obra Manifesto Contrassexual, em que coloca em questão o que chama de "regime heterocentrado" - uma normatização naturalizada das identificações sexuais binárias - e problematiza a ordem que se estabelece e se legitima na exclusão de corpos entendidos como abjetos. O termo contrassexualidade se apresenta como uma possibilidade de ressignificação da produção disciplinar relacionada à sexualidade moderna, uma vez que propõe formas que a autora qualifica como contraprodutivas, para desconstruir a naturalização de práticas sexuais normativas e do sistema sexo-gênero. Preciado (2014), com certo tom provocativo e debochado, recorre a uma analogia ao dildo, um pênis de borracha, para discutir a naturalização das dicotomias heterocentradas, associadas ao sexo, à sexualidade e ao gênero.

Entre os princípios da sociedade contrassexual que propõe, destacamos a ideia de extinguir denominações como "masculino" e "feminino", criar novos nomes sociais que escapem às marcas de gênero, abolir o contrato matrimonial, ressexualizar o ânus, descentralizar a significação de poder do pênis e colocar em funcionamento práticas sexuais subversivas (PRECIADO, 2014).

Em outro artigo, reafirma sua contestação a todas as políticas e ordens de conhecimento que se remetem a identidades plenas e unitárias, cunhando a expressão "multidões queer": "De noção posta ao serviço de uma política da reprodução da vida sexual, o gênero se torna indício de uma multidão. [...] As minorias sexuais tornam-se multidões" (PRECIADO, 2011, p. 14). Recusa o gueto para essas minorias/multidões, recorrendo a "estratégias ao mesmo tempo hiperidentitárias e pós-identitárias", para questionar a estabilidade e contenção da diferença sexual: "Não existe diferença sexual, mas uma multidão de diferenças, uma transversalidade de relações de poder, uma diversidade de potências de vida". A autora destaca ainda a dimensão epistêmica da sua proposição, que coloca em questão "também os sistemas de produção de saberes científicos dos 'normais"' (PRECIADO, 2011, p. 18).

Aqui no Brasil, a teoria queer foi apropriada inicialmente pelo campo da Educação, a partir dos estudos de Guacira Lopes Louro, uma das mais reconhecidas pesquisadoras das temáticas gênero e da sexualidade e hoje professora aposentada da Universidade Federal do Rio Grande do Sul. Miskolci (2013) analisa a entrada dos estudos queer no Brasil pela Educação, relacionando-a com as demandas e tensões que o processo de democratização pós ditadura militar colocou para o país, já que, com a universalização do ensino básico, professores e professoras mostraram-se incapazes de lidar com as diferenças socioeconômicas, raciais, de gênero e sexualidade, ou aquelas denominadas como deficiência, silenciadas durante anos e que clamavam por reconhecimento e aceitação no espaço escolar.

Em sua obra mais clássica sobre a temática, denominada Um corpo estranho: ensaios sobre sexualidade e teoria queer, Louro (2008) discute conceituações básicas e iniciais sobre a teoria, remetendo-a a Jacques Derrida, Judith Butler e Michel Foucault, e propondo pensar o campo da Educação nessa perspectiva. Postula que conceber uma pedagogia ou currículo queer implica focalizar os processos de reconhecimento e de produção das diferenças, entendendo a instabilidade e a precariedade das identificações de gênero e sexualidade das/dos estudantes, não apenas para denunciar as exclusões vividas por sujeitos tidos como abjetos, como também e, sobretudo, para desconstruir os mecanismos pelos quais apenas a forma binária do gênero e da sexualidade é legitimada. Nas suas palavras:

\footnotetext{
${ }^{16}$ Beatriz Preciado hoje inseriu "Paul" em seu nome, todavia, declara não se reconhecer como homem e nem como mulher e que seu objetivo é "dinamitar" esse binômio, afirmando a multiplicidade infinita do sexo (PRECIADO, 2014). Referimos, então, conforme seu nome é identificado nas obras aqui citadas: Preciado, Beatriz, autora.
}

Práxis Educativa, Ponta Grossa, v. 12, n. 2, p. 481-500, maio/ago. 2017 Disponível em: <http://www.revistas2.uepg.br/index.php/praxiseducativa> 
Ao se dirigir para os processos que produzem as diferenças, o currículo passaria a exigir que se prestasse atenção ao jogo político aí implicado: em vez de meramente contemplar uma sociedade plural, seria imprescindível dar-se conta das disputas, das negociações e dos conflitos constitutivos das posições que os sujeitos ocupam (LOURO, 2008, p. 48-49).

A partir das proposições aqui sumarizadas, defendemos que a teorização queer oportuniza o reconhecimento da infinitude potencial do gênero e do desejo sexual, e pode favorecer a problematização das repetições e dos deslocamentos relativamente a preconceitos e discriminações por questões dessa ordem nas práticas da EFE.

Observamos, contudo, não haver construção teórica desenvolvida especificamente voltada para a problematização dos processos sociais de construção do masculino, nessa perspectiva, projeto cuja urgência já anunciamos na introdução deste artigo. Com base nas teorizações queer, em que destacamos sua fundamentação na desconstrução derridiana, concluímos esta reflexão propondo duas noções/operadores de pesquisa que poderão apoiar a investigação acadêmica sobre tal temática em uma abordagem mais radical da inclusão: masculinidade normalizadora e masculinidade queer.

\section{Horizontes queer}

Conforme já assinalamos, na discussão do artigo de Chaves (2015), não inauguramos a referência à perspectiva queer na pesquisa sobre as questões da masculinidade na Educação Física. $\mathrm{O}$ que pretendemos, com a proposição dos operadores de pesquisa masculinidade normalizadora e masculinidade queer, é contribuir para um maior desenvolvimento dessa abordagem, em cuja potência apostamos, visando à radicalização da proposta da inclusão das identificações e performances de gênero e do desejo sexual divergentes da heteronormatividade, no contexto da EFE.

Com a expressão masculinidade normalizadora, pretendemos nomear as enunciações do ser bomem que, em espaços-tempos arbitrados pela pesquisa, logram afirmar, ainda que de forma precária e contingente, os parâmetros de normalidade dessa experiência e identificação. A masculinidade queer, por outro lado, denomina um horizonte político, que avaliamos como radicalmente favorável à bandeira da inclusão na educação em geral, e na EFE, em particular: não define propriamente um formato de masculinidade, antes nos convida a problematizá-la e a duvidar de qualquer estabilização identitária que se pretenda necessária e não contingente.

Não se trata de conceitos - ao menos, não no sentido mais tradicional da sua significação na pesquisa acadêmica -, posto que seus conteúdos se constituem por convites a problematizações, desejos e resistências, e não por afirmações fechadas de sentidos: a noção de masculinidade normalizadora não se define por características do masculino prévias à indagação contingente quanto às disputas travadas pelo estabelecimento do normal masculino em quadros específicos. Remete-se à concepção performativa do gênero (BUTLER, 2012, entre outros títulos já citados), ressaltando - mas também relativizando - a força das enunciações cotidianas e locais do que é autorizado e do que é reprimido nas vivências da masculinidade nos contextos em discussão.

Já a masculinidade queer opera como um horizonte político, que aponta para além da pluralidade da identidade de gênero e da orientação sexual, radicalizando a abertura ao devir do desejo e potencializando ao infinito o reconhecimento positivo da diferença do gênero e da sexualidade. 
Isso, com efeito, renova a questão: e se estivéssemos alcançando aqui, e se estivéssemos nos aproximando aqui (já que isso não se alcança como a um lugar determinado) o espaço de uma relação com o outro, na qual o código das marcas sexuais não fosse discriminador? Relação, então, já não assexuada, nem tampouco menos sexualizada, mas sexualizada de outra maneira, para além da bissexualidade, da homossexualidade ou $\mathrm{da}$ heterossexualidade, que resultam na mesma coisa (DERRIDA; MCDONALD, 2008, p. 171; tradução nossa ${ }^{17}$ ).

Pensadas em articulação mútua, no contexto teórico-político da desconstrução, preferimos qualificá-las como operadores de pesquisa, que se traduzem também em questões de investigação: operar com a noção de masculinidade normalizadora nos estudos acadêmicos, no sentido que estamos propondo, implica necessariamente indagar a respeito das estabilizações que orientam o que/quem se inclui ou se rejeita nas práticas da EFE; ter a noção de masculinidade queer como horizonte político traz questões às novas estabilizações que se colocam quando da desconstrução do que já se encontra sedimentado. Visam, assim, garantir a suspeita como postura epistêmica que incomoda, sem trégua, a atividade de pesquisa.

Entendemos que a postura epistêmica da permanente suspeita é imprescindível quando se trata da inclusão na Educação, dadas as apropriações politicamente conservadoras de que tal proposta tem sido alvo. Discutindo sobre a trajetória político-social da perspectiva da inclusão, com base na teoria do discurso em Ernesto Laclau, o cientista político Joanildo Burity (2006, p. 47) afirma que

Como acontece com todos os significantes políticos que conseguem galvanizar a atenção e/ou a adesão dos atores sociais em disputa pela hegemonia, 'inclusão social' ao mesmo tempo em que se abriu para nomear os horizontes da mudança desejada, incorporando uma gama enorme de situações de subordinação, marginalidade e opressão, perdeu em significado preciso. Passando a ser reivindicada e utilizada por todos - quem poderia defender a exclusão? - a inclusão social tornou-se dependente de quem a enuncia e das articulações entre atores sociais e políticos concretos, para adquirir conteúdo específico $[\ldots]$.

Concordando com o autor, defendemos que o horizonte político queer direciona a atenção da pesquisa e das práticas da EFE às armadilhas da inclusão conservadora, isto é, da inclusão que propõe inserir a diferença sem questionar o próprio contexto de inserção. Não propomos domesticar as multidões do gênero e do desejo sexual para que se integrem em ambientes tolerantes que não rompem de forma radical com a normalização da diferença. Propomos, sim, a subversão queer da normalidade opressora da Educação Física escolar que não reconhece a beleza potencial do imprevisível da existência.

\section{Referências}

ALMEIDA, S. C. F. Artes marciais e masculinidades: relações modernas para culturas tradicionais. In: CONGRESSO BRASILEIRO DE CIÊNCIAS DO ESPORTE, 19.; CONGRESSO INTERNACIONAL DE CIÊNCIAS DO ESPORTE, 6., 2015, Vitória. Anais... Vitória: UFES, 2015. p. 1-13.

\footnotetext{
17 "Esto renueva en efecto la cuestión: y si estuviéramos alcanzando aquí, y si nos estuviéramos acercando aqui (ya que eso no se alcanza como un lugar determinado) a la zona de una relación con el otro en la que el código de las marcas sexuales no fuera ya discriminante? Relación, entonces, ya no assexuada, ni mucho menos, sino sexuada de otra manera, más allá de la bisexualidad, de la homosexualidad o de la heterosexualidad que resultan ser lo mismo"
}

Práxis Educativa, Ponta Grossa, v. 12, n. 2, p. 481-500, maio/ago. 2017 Disponível em: <http://www.revistas2.uepg.br/index.php/praxiseducativa> 
ANDRES, S. S.; JAEGER, A. A.; GOELLNER, S. V. Educar para a diversidade: gênero e sexualidade segundo a percepção de estudantes e supervisores do Programa Institucional de Bolsa de Iniciação à Docência (UFSM). Revista da Educação Física, Maringá, v. 26, n. 2, p. 167-179, 2015. DOI: 10.4025/reveducfis.v26i2.23016

ANDREOLI, G. S. Representações de masculinidade na dança contemporânea. Movimento, Porto Alegre, v. 17, n. 1, p. 159-175, jan./mar. 2011.

ANJOS, L. A. "Vôlei masculino é pra homem": representações do homossexual e do torcedor a partir de um episódio de homofobia. Movimento, Porto Alegre, v. 21, n. 1, p. 11-24, jan./mar. 2015.

BENTO, B. Na escola se aprende que a diferença faz a diferença. Revista Estudos Feministas, Florianópolis, v. 19, n. 2, p. 32-48, maio/ago. 2011. DOI: 10.1590/S0104-026X2011000200016

BRITO, L. T.; SANTOS, M. P. Masculinidades na Educação Física escolar: um estudo sobre os processos de inclusão/exclusão. Revista Brasileira de Educação Física e Esporte, São Paulo, v. 27, n. 2, p. 235-246, 2013. DOI: 10.1590/s1807-55092013000200008

BURITY, J. A. Cultura e identidade nas políticas de inclusão social. In: BURITY, J. A.; AMARAL JR, A. (Orgs.). Inclusão social, identidade e diferença: perspectivas pósestruturalistas de análise social. São Paulo: Annablume, 2006. p. 39-66.

BUTLER, J. Excitable speech. A politics of the performative. Nova Iorque: Routledge, 1997.

BUTLER, J. Deshacer el género. Barcelona: Paidós, 2012.

BUTLER, J. Problemas de gênero. Feminismo e subversão da identidade. Rio de Janeiro: Civilização Brasileira, 2015a.

BUTLER, J. Quadros de guerra: quando a vida é passível de luto. Rio de Janeiro: Civilização Brasileira, 2015b.

CASTELLANI FILHO, L. Educação Física no Brasil: a história que não se conta. Campinas: Papirus, 2013.

CHAVES, P. N. Estigmas do Corpo, Gênero e Sexualidade no Esporte: voleibol enquanto espaço da mulher e da 'Bicha'. In: CONGRESSO BRASILEIRO DE CIÊNCIAS DO ESPORTE, 19.; CONGRESSO INTERNACIONAL DE CIÊNCIAS DO ESPORTE, 6., 2015, Vitória. Anais... Vitória: UFES, 2015. p. 1-14.

CECCHETTO, F. R. Violência e estilos de masculinidade. Rio de Janeiro: FGV Editora, 2004.

CONNELL, R. Políticas da masculinidade. Educação e Realidade, Porto Alegre, v. 20, n. 2, p. 185-206. jul./dez., 1995.

CONNELL, R. The men and the boys. Berkeley: The University of California Press, 2000.

CONNELL, R. Masculinidades. México: UNAM-PUEG, 2003. 
CONNELL, R. Masculinidade corporativa e o contexto global: um estudo de caso de dinâmica conservadora de gênero. Cadernos Pagu, Campinas, v. 40, p. 323-344, 2013. DOI: 10.1590/S0104-83332013000100010.

CONNELL, R.; MESSERSCHIMIDT, J. W. Masculinidade hegemônica: repensando o conceito. Revista Estudos Feministas, Florianópolis, v. 21, n. 1, p. 241-280, jan./abr. 2013. DOI: 10.1590/S0104-026X2013000100014

CONNELL, P.; PEARSE, R. Gênero: uma perspectiva global. São Paulo: nVersos, 2015.

CUNHA JR, C. F.; MELO, V. A. Homossexualidade e Educação Física: estereótipos, preconceitos e discriminações. In: REUNIÃO ANUAL DA ANPED, 19., Caxambu. Anais... Caxambu, 1996.

DERRIDA, J.; MCDONALD, C. V. Coreografias. Lectora: revista de dones i textualitat, Barcelona, n. 14, p. 157-172, 2008.

DEVIDE, F. et al. Estudos de gênero na Educação Física Brasileira. Motriz: Revista de Educação Física, Rio Claro, v. 17, n. 1, p. 93-103, 2011. DOI: /10.5016/19806574.2011v17n1p93

FERRARI, A. O que se fala e o que se cala sobre o homoerotismo masculino: discursos, práticas e posturas dos professores diante do fato e do assunto. In: REUNIÃO ANUAL DA ANPED, 23., 2000, Caxambu. Anais... Caxambu, 2000. p. 1-17.

FORTH, C. E. Masculinidades e virilidades no mundo anglófono. In: CORBIN, A.; COURTINE, J. J.; VIGARELLO, G. (Orgs.). História da virilidade. A virilidade em crise? Petrópolis: Vozes, 2013. v. 3. p. 154-188.

GOETTEMS, L.; SCHWENGBER, M. S. V. Feminilidades e masculinidades: os entrelugares na e da escola. In: CONGRESSO BRASILEIRO DE CIÊNCIAS DO ESPORTE, 18.; CONGRESSO INTERNACIONAL DE CIÊNCIAS DO ESPORTE, 5., 2013, Brasília. Anais... Brasília: 2013. p. 1-19.

KNIJNIK, J. D. et al. De menino a homem: a mídia e a construção de masculinidades esportivas. In: CONGRESSO BRASILEIRO DE CIÊNCIAS DO ESPORTE, 15.; CONGRESSO INTERNACIONAL DE CIÊNCIAS DO ESPORTE, 2., 2007, Recife. Anais... Recife: 2007. p. $1-12$.

LEITE, M. A perspectiva multi/intercultural na Educação: as reuniões anuais da ANPEd (19942002). In: CANDAU, V. M. (Org.). Educação intercultural e cotidiano escolar. Rio de Janeiro: 7Letras, 2006. p. 77-98.

LEITE, M. Violência e homofobia na escola. In: CANDAU, V. M. (Org.). Didática crítica intercultural. Aproximações. Petrópolis: Vozes, 2012. p. 191-215.

LOURO, G. L. Um corpo estranho: ensaios sobre sexualidade e teoria queer. Belo Horizonte: Autêntica, 2008. 
MISKOLCI, R. Teoria queer: um aprendizado pelas diferenças. Belo Horizonte: Autêntica, 2013.

MOIOLI, A. et al. Soccer and homosexuality: The conflicts that lie within the affective game of the coach-adolescent athlete relationship. Motriz: Revista de Educação Física, Rio Claro, v. 20, n. 4, p. 346-358, 2014. DOI: 10.1590/S1980-65742014000400001

PASSOS, D. et al. As origens do "vale-tudo" na cidade de Curitiba-PR: memórias sobre identidade, masculinidade e violência. Movimento, Porto Alegre, v. 20, n. 3, p. 1153-1173, jul./set. 2014.

PINTO, J. P. Atos de autoria: assinaturas, rasuras, rupturas. Revista Investigações, Recife, v. 22, n. 1, p. 103-110, 2009.

PRECIADO, B. Multidões queer: notas para uma política dos "anormais". Estudos Feministas, Florianópolis, v. 19, p. 11-20, n. 1, jan./abr. 2011. DOI: 10.1590/S0104-026X2011000100002

PRECIADO, B. Manifesto contrassexual: práticas subversivas de identidade sexual. Tradução de Maria Paula Gurgel Ribeiro. São Paulo: N1 edições, 2014.

RODRIGUES, C.; ANDRADE, D.; MANO, M. K. Por uma Teoria Social de Gênero do e para o Sul Global: uma entrevista com Raewyn Connell. Revista Feminismos, Salvador, v. 3, n. 1, 2015.

SANCHO, J. M. et al. Masculinidade hegemônica, esportes e atividade física. Movimento, Porto Alegre, v. 16, n. 4, p. 93-115, 2010.

SANTIAGO, M. C.; SANTOS, M. P. Planejamento de Estratégias para o Processo de Inclusão: desafios em questão. Educação e Realidade, Porto Alegre, v. 40, n. 2, p. 485-502, 2015. DOI: $10.1590 / 2175-623645248$

SANTOS, V. C. Indícios de sentidos e significados de feminilidade e masculinidade em aulas de Educação Física. Motriz: Revista de Educação Física, Rio Claro, v. 16, n. 4, p. 841-852, 2010. DOI: 10.5016/1980-6574.2010v16n4p841

SCOTT, J. Prefácio a Gender and politics of history. Cadernos Pagu, Campinas, n. 3, p. 11-27, 1994.

SCOTT, J. Os usos e abusos do gênero. Projeto História. Revista do Programa de Estudos Pós-Graduados de História, São Paulo, n. 45, p. 327-351, 2012.

SILVA JUNIOR, P. M.; CANEN, A. O que dizem as teses e dissertações sobre questões de sexualidades, masculinidades e gênero nas escolas? Educação em Perspectiva, Viçosa, v. 6, p. 10-35, 2015.

SILVA, P.; BOTELHO-GOMES, P.; GOELLNER, S. V. Educação Física no sistema educativo português: um espaço de reafirmação da masculinidade hegemônica. Revista Brasileira de Educação Física e Esporte, São Paulo, v. 22, n. 3, p. 219-233, 2008. DOI: 10.1590/S180755092008000300006 
SOARES, C. L. Pedagogias do corpo: higiene, ginásticas, esporte. In: RAGO, M.; VEIGA NETO, A. (Orgs.). Figuras de Foucault. Belo Horizonte: Autêntica, 2006. p. 75-85.

SPARGO, T. Foucault e a teoria queer. Rio de Janeiro: Pazulin; Juiz de Fora: Ed. UFJF, 2006.

WARNER, M. Fear of a queer planet: queer politics and social theory. Minnesota: Minnesota Press, 1993.

Recebido em 31/05/2016

Versão corrigida recebida em 10/10/2016

Aceito em 20/10/2016 